\title{
THE AESTHETIC VALUE OF SOCIO-CULTURAL IDENTITIES AND THE CULTURAL DIMENSION OF THE LANDSCAPE
}

\author{
Lazaros Elias Mavromatidis* \\ MAP Aria Laboratory, UMR 3495, Ecole Nationale Supérieure d'Architecture de Lyon, France
}

\begin{abstract}
This paper summarizes an individual theoretical study on how the landscape could be shaped by economic globalization and political restructuring. Providing a socio-cultural approach to the landscape notion I am trying to discover through the international literature the subjective dimension on landscape definition, in order to understand its 'cultural dimension'. In this paper, the notion of 'virtual landscape' is introduced in order to investigate the incoherence that exists in the nowadays megacities regarding their social reality and their iconic existence through architecture and urban planning. In addition, it is also explored in theory how an ideological turn is re-inforced through political orientation focusing on 'virtual landscape' images in order to obtain a favorable publicity in a contemporary context of 'globalised cities' consisting in the elimination of the 'cultural landscape'. Therefore, this contribution has as main objective to define, negotiate and start the debate on radical socio-cultural approaches of landscape notion in the nowadays 'megacities', inside a strict capitalist context.
\end{abstract}

Key words: Cultural landscape, Virtual landscape, Re-scaling, Urban planning, Globalisation.

Article Info: Manuscript Received: April 3, 2012; Accepted: August 15, 2012; Online: November 30, 2012.

\section{Introduction}

Urban iconic dimension deals with the need to define the abstract term 'landscape', in order to understand in which degree the economic and political context can influence a city's structure and texture. Geographers by theorizing the human visual perception firstly gave to the term 'landscape' a direct connection with the natural elements of the space. Nowadays, it is commonly accepted that the contemporary life is shaped into a continuous framework of excessive information that opens up diverse realities and visual cognitions. According to Jackson (1986) the public's use of the word 'landscape' appears to

'encompass either scenery or the depiction of scenery or that which visually relays an aesthetic experience' (Jackson, 1986).

\footnotetext{
* Correspondence address:

Address: 3 rue Maurice Audin, BP 170, 69512, Vaulx-en-Velin Cedex, France

Telephone: +33.04 7.8 79.5085

Email: lazaros.mavromatidis@aria.archi.fr
}

Various researchers and practitioners were moved towards a definition which includes 'biological and ecological processes and conditions' (Beza, 2010; Daniel, 2001), having as purpose to dissociate the landscape definition from the western dictionary meanings. For example Beza, claims that the general term of landscape is flexible in use, referring to 'constructed and natural environments, macro-scales and micro-scales and physical and cognitive concepts' (Beza 2010). Therewith, the above mentioned definitions don't underline the subjectivity of the human visual perception and ignore the presence of social structures inside the 'landscape field of study'. In contrario, Tuan tries to give this subjective dimension by describing the 'landscape' as 'a construct of mind and feeling' (Tuan, 1979). Kant also had given a subjective definition however he underestimated the feeling perception by defining the landscape as a 'construct of one's cognition of what is being observed' (Kant, [1790] 2000). The important issue in both of the above perceptions is that the

'resulting perception is a reflection of culture and experiences and depends on whether one is a visitor or a native to an environment' (Beza, 2010; Tuan, 1974). 
However, the presence of real social and cultural factors inside the area of study is always absent in these definitions.

In this contribution, I will try to present a brief review of the literature regarding the cultural dimension of the landscape based on the insertion of the subjective dimension in its definition. Furthermore I employ the approach that the economic-political organization of the human societies with the passing of the time converted the notion of 'cultural landscape' to 'virtual landscape' by rejecting the iconic expression that didn't serve the social interests that controlled the architectural creation, having as result to delete the capacity of the 'iconic expression' to contest in a social level the Foucauldian "state of disciplines" (Foucault, 1993) of each historical period. In addition, I articulate that this "state of disciplines" that characterizes each historical period guides the society to produce through architecture the necessary symbols in order to identify itself through time. Furthermore, considering Kaika's (2011) spatial interpretation of 'radical imaginary' based on Castoriadis' definition, I try to reposition the 'cultural landscape' by understanding and evaluating the influence of the new reconceptualization patterns on the production of urban space and landscape, requested by the transnational decision centers and institutions.

\section{'Cultural' and 'virtual' dimensions of the landscape definition}

Following Beza's literature, we discover that he tried to strip the 'landscape' notion of implied meaning by suggesting that

'the landscape consists of horizontal and vertical elements [where] meaning is ascribed through a combination of these features and one's cognition, the resulting perception is the landscape' (Beza, 2005, p.56),

insisting always to neglect the original social elements inside his field of study. Therewith, the above definitions may either guide us towards a subjective 'landscape' notion or towards an abstract articulate that the landscape is a 'place', where 'place' could be defined by various researchers on the one hand as ' $a$ personal connection created from experience, perception and value of the environment' (Green, 1999; Cheng et al., 2003; Sevenant and Antrop, 2007; Beza, 2010) or one's 'particular fusion of landscape and imagination' on the other hand (Ryden, 1993). Even if these landscape definitions insist on theorizing the way of seeing the land, by neglecting the social relations upon it, they dissociated the term landscape from its pure environmental notion, associating it with the 'place' notion.

Nevertheless, nowadays few will deny that in a social contemporary network the landscape has also an important cultural dimension. Dimaggio (1982), Zukin (1991; 1995) and Scott (1997) conjugated theoretically place and culture. Place is defined as a 'topos' (in greek тóroc = space, locus) where dense human interrelationships are reproducing continuously and culture is a social phenomenon that inherits its specific characteristics by the place where it is born and reproduced, while simultaneously it helps to differentiate places from one another (Dimaggio, 1982; Zukin, 1991; 1995; Scott, 1997). Similarly, there are many researchers that treated also the landscape issues considering social and cultural factors as main entities inside the 'landscape' field of study, by inserting the notion of 'cultural landscape. According to Sauer geographers should always have looked at the 'cultural landscape' as the 'material reflection of how human culture impacts the natural world' (Sauer, 1925). Cosgrove (1983) underlined the social dimension of the landscape by studying how landscape is both a pictorial representation and 'way of seeing' the land and social relations upon it. Furthermore, Duncan (1990) claimed that the 'landscape is a kind of a text, through which powerful discourses are inscribed by competing social forces' (Duncan, 1990: cited in Prytherch, 2003). Mitchell (1996, 2000) investigated how the landscape could be both a sphere of capitalistic production and a representation of it that in the same time could be able to obscure social struggles existing within the landscape. Czepczyński (2008) focusing on visual aspects of the urban scenery and their shifting readings, proposed using the concept of 'cultural landscape' as an analytical tool for further understanding of the complex relationship between urban materiality and social and cultural transformation (Figure 1).

As a conclusion of the above literature study, what else could be a 'cultural landscape' in a contemporary city if not the assimilation of the ethnic, social, gender, economical and local characteristics on a built environment manufactured by human beings? The socio-cultural identity and the non-economic factors interact with the built environment and are transformed into image by architecture and urban planning. This is why

'cultural landscape can be interpreted as an announcement / revelation / exposure of information about local societies' (Czepczyński 20o8: pp. 2).

Therefore, in a globalised context the landscape creation has no relation with the socio-cultural actuality of the contemporary societies and the existed 'cultural landscape' is systematically neglected. I 
would name 'virtual landscape' this landscape that results, by ignoring the socio-cultural aesthetic forms and values of the contemporary cities, in order to form a 'virtual' marketing image (Mavromatidis, 2010).

\section{Marketing and virtual image of contemporary cities}

Hence, in marketing-communication terms, inside a globalised context, images play an important marketing role in the creation of a 'virtual landscape' (Mavromatidis, 2010), because they affect perceptions and various spatial decisions made by three different groups according to Avraham: i) the general public, ii) decision makers on a national and international level and iii) the place's inhabitants (Avraham 200o). Avraham (2000) deeply studied the media images and concluded that

'the media portrayal has implications for the position of cities in the growing international and national competition for various resources such as tourism, businesses and investments'.

Having on mind the Straus' (1961) opinion who claims that when talking about cities there is a tendency to stereotype them, numerous researchers remarked that this stereotype creation is the reason that changes are not reflected in the places' coverage patterns when occur in such places, (Avraham, 20oo;
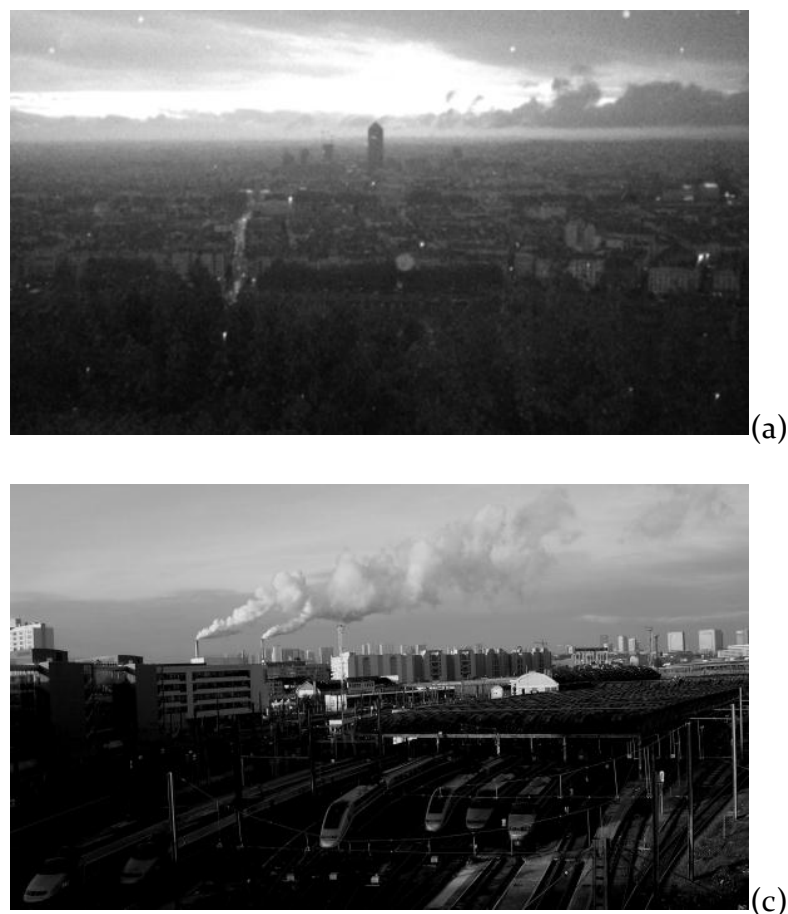

Elizur, 1994; Graber, 1989). For that reason, a place becomes a symbol of a certain type of activities and events when is labeled by the media as being one in which only occur such events (Avraham, 200o). In every case, this fact can be remarked observing the media image of the city in comparison with the apparent social reality. The local characteristics and dynamics, the cultural and historical background and the political evolution of every city need to be further analyzed as they could help to further understanding of the above mentioned opinion. So to answer the question why there is a need to create 'virtual landscape images', suffice it to employ Molotch's explanation where (1996: pp. 229)

'the positive connection of product image to place yields a kind of monopoly rent that adheres to places their insignia and the brand names that may attach to them'.

Molotch (1996) also claims that favorable images of a place can create entry barriers for products or services from competing places.

For these reasons, several researchers focused on the notion of the cultural economy of capitalist cities by underlying that it targets in the commercialization of the historical heritage and in large-scale public investments promoting collective cultural consumption due to urban renovation (Wynne, 1992; Bassett, 1993; Scott, 1997). Nevertheless, once again the 'cultural landscape' notion is being modified in order to assimilate
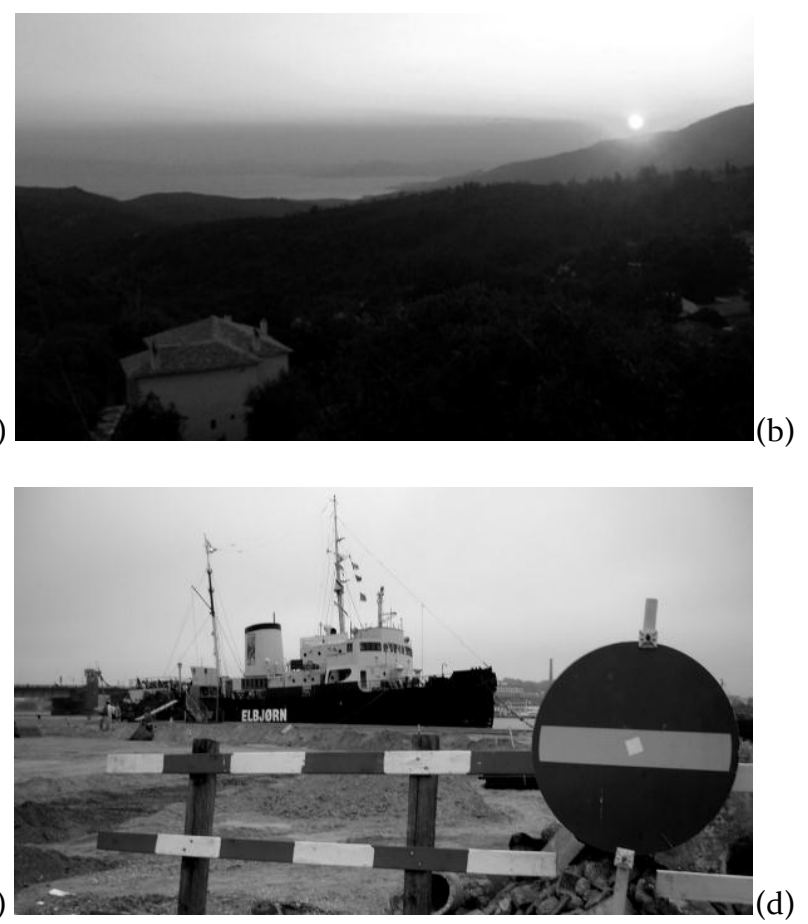

Figure 1: We can use the concept of 'cultural landscape' as analytical tool, in order to understand deeper the complex relationship between urban materiality and social and cultural transformation. (a) Lyon, (b) Neohori of Pelion, (c) Paris,

(d) Aalborg. (ㄷ Lazaros Elias MAVROMATIDIS) 
'emergent forms of cultural identities which are partly incorporated in the logic of globalization due to its innovational character especially in the technological field' (Ntaras, 2001).

From the other side, in a kind of a contemporary international 'virtual landscape' competition of city images, many cities constitute the weak point with a much lesser level of international projection. Some districts were 'very degraded' and a new kind of 'urban regeneration' is promoted to correct deficiencies in the urban fabric in order to create new poles of growth. Therewith inside a 'global' context, in this new re-scaled urbanization, tourist and commercial activities which are derived by 'globalizing consumption patterns' (Erkip, 200o) increase social inequality among citizens, by attempting at the same time to attract foreign and corporate capital (Tokatlí and Boyací, 1999). So new cosmopolitan elite creates a 'virtual landscape' in the new metropolitan plan of the city, by founding the new urban projects. And this 'virtual landscape' is sometimes demanded by the inhabitants of the cities with no important image in the 'global' scene. For example, in post-socialist countries, people after 1990 were bombarded by the variety of images and information without being culturally educated to filter them and select the most reliable (Kulcsar and Domokos, 2005). This is why the local elites who have promising agendas are popular and there is sometimes a strong desire for almost any type of development, especially in a visible physical form through architectural expression, by ignoring in the same time the negative side effects of development (Kulcsar and Domokos, 2005). Nevertheless, in this case urban development is whether driven by a coherent coalition of elites who benefit from local population expectations than by supply and demand of useful infrastructures (for further development see also Molotch (1976) and his concept of the growth machine). The argument that 'elites are cosmopolitan, people are local' (Castells, 1996, p. 415; Ntaras, 2001) is always relevant and generally concern every city inside a 'global' concept.

Nowadays, the contemporary post-modern Foucauldian 'state of disciplines' constructed a net where cities are invited to affect their own 'virtual landscape' media image by public relations and promotional efforts, even if it is not possible to control the socio-cultural context, the editorial decisions or most of their socio-cultural identities (Avraham, 200o). According to Gans (1979) and Ryan (1991) the ability of a place to affect its images in the media and successfully market itself necessities vast resources and a strong connection to economic power. Gold and Ward (1994) defined 'place promotion' as 'the conscious use of publicity and marketing to communicate selective images of specific geographical localities or areas to a target audience'.

Furthermore, the 'target audience' in a contemporary globalised net is the tourists, the upper/new middle class (international or/and local) and the businesses. The political orientation intends to create a new metropolitan life-style of middle and upper income groups by completing the need for 'phantasmic seduction' (Žižek , 1989: pp.1; cited in Kaika, 2011) through 'iconic' architectural production according to Kaika's (2011) research. Considering the new consumption patterns and nowadays social reality, hotels, shopping malls and private universities always have the ability to attract the investors as the most profitable area by affecting, in the same time, the 'cultural landscape' of the contemporary cities. Additionally, it is clear that a new distribution of power between central and local governments, in economies in crisis could render urban land more available for big construction national or multinational companies.

However, Erkip (200o) claims that 'exhaustive consumption of globally promoted goods and life-styles increases social segregation'. This segregation is reinforced by the fact that the articulation with the world economy seem to be helped by the main policy issue in order to render any city more attractive for international and local capital. Additionally, according to Cox (1995) the

'local economic development policies to attract business in a competitive environment, are likely to sustain and even support the inequalities in the distribution of benefits'.

That's why the two major socio-cultural identities named as 'cosmopolitanism' and 'exclusionism' by Ntaras (2001), become apparent in every city and menace its 'cultural landscape'. The new born architectural and urban projects impose a new 'virtual landscape' by creating gated communities with security-guards. In this case, the dominant factor for upper income groups to create a life-style based on the new consumption patterns, is the income level and in this case the real danger is that this 'virtual landscape' could be transformed with the passing of time, into a new 'cultural landscape', destroying the socio-cultural identity of the 'place'. In which degree this 'virtual landscape' could be assimilated depends on the socioeconomic future of the country. If this new metropolitan lifestyle dominates, the past will be eliminated from the cultural landscape image of a society. 


\section{Conclusion: need for a new kind of governance and regional development}

In order to preserve the cultural dimension of the contemporary landscape, social scientists, geographers and decision makers have long understood and expressed in a theoretical and scholar level that the nowadays government strategies and the regional development should cope with ever growing problems of contemporary metropolitan cities based also on non-economic factors (Castells, 1977; 1978; 1996; Hadjimichalis and Vaiou, 1990; Erkip, 1997; Green, 1999; Ntaras, 2001; Prytherch, 2003; Hadjimichalis 2006; Hadjimichalis and Hudson 2006; Sevenant and Anthrop, 2007). Urban redistribution, housing problems, inequality, unemployment, and the problems of social justice could be stated as the most important problems of the nowadays 'megacities' (Erkip, 200o), that should be in coherence with the 'cultural landscape' of a city. Architectural creation may influence this cultural dimension of the landscape, because, architecture is not a simple 'form creation' but first of all it is a spatial distribution, in a specific space and time.

Hence, as a conclusion of the above theoretical analysis, I argue that before creating, it is important to think deeply on the social, cultural and aesthetic impact of the architectural creation, and there is always an impact in various dimensions (Mavromatidis, 2010). However, the research process of urban 'territory's' socio-cultural value is not a simple social investigation; it's a theoretical position that denies the autonomy of the urban planning datum level (Karidis, 2008, p.15). Nowadays, it is clear that the urban policies of the past had never been welfare-oriented by excluding social and cultural factors from the decision making procedure and the landscape of a city, while it is also clear that market and outward orientation had never been so dominant by neglecting some non-economic factors such as 'social capital', 'reciprocity' and 'trust' that appeared recently in scholar publications (Putnam 1993; Porter 1998; Hadjimichalis, 2006). Furthermore, according to Erkip (2000), an apparent fragmentation of citizens into segments with different expectations and lifestyles is indicated after analyzing the recent political developments in Europe, Asia and United States transforming the 'cultural' into 'virtual' landscape. However, according to Hadjimichalis' approach of agglomeration economies and regional development the above mentioned non-economic factors could be analyzed in order to explain why some regions are more dynamic than others (Hadjimichalis, 2006), by leading towards new strategies of governance and democratic regional political environment, preserving the aesthetic value of socio-cultural identities.

The necessity of a new kind of governance and regional development is also proved by the fact that lot of empirical researchers on decision making field, like Green, discovered, that there are frequent complaints from ordinary citizens concerning the 'character' of their local environment which is lost 'due to incompatible development and associated environmental changes' (Green, 1999). In response to these concerns, Green (1999), Habe (1989) and Southworth (1989) underlined an abstract need for preserving a stable framework of familiar and valued environmental features that express the local character presenting very 'romantic' views on reterritorialisation 'fostering an image of altruism and self-sacrifice, as opposed to opportunism' (Hadjimichalis, 2006). Nevertheless, this abstract necessity of potential 'cultural landscape' creation has become an increasingly important concern of urban and landscape planning practice (Green, 20oo; Habe, 1989; Southworth, 1989) in order to guide capitalist societies through a cooperation with the disadvantaged social structure which have no space in the nowadays megacities such as gender and immigrants etc.

Although the above mentioned models of analysis enriched our agendas in the past, today these models have come to a dead end and their 'treatment of noneconomic issues is highly compatible with a neoliberal view' (for a detailed analysis see also Hadjimichalis, 2006). This statement is also reinforced by the Hegelian 'coincidences of the opposites' where a statement turns into its opposite the moment we consider its space of articulation (Žižek , 1992). For example the reference of a neoliberal institution to a non-liberal context constitutes exactly the form of appearance of the opposite idea of the pronounced context and is nothing but a strategy to assume hegemony in the ideological struggle (Žižek , 1992). In this framework, architecture providing the symbols of this 'hidden' neoliberal era, act as the mean to constitute the visible or invisible instituted authority that express as real (Kaika, 2010; see also Castoriadis, 1987: cited in Kaika 2010; Kavoulakos, 2006: cited in Kaika, 2010). These symbols seem to cope with contemporary inequalities by providing a new kind of sustainable and environmental friendly space, however these new 'iconic architectural items' deliver ephemeral images in the cityscape because they are conceived as territorial elements and not as space envelopes. This reduction of space to 'territory' converts landscape creation to a simple planning procedure that has to fulfill a number of assignments. And finally, landscape creation and architecture lose the notion of a social art becoming the tool of official or unofficial institutional intervention in the territorial allocation and the 'virtual landscape' transformation. 


\section{Acknowledgements}

I dedicate this work to Anniouta, my parents Elias and Stamatina, Assimina, Semina and Pinelopi for encouraging me all this period and Nikos for his 'virtual' encouragement even if I know that maybe he will never read these lines. I would like to express my greetings to Christos Mantzikas for his help and his advices. Finally, I gratefully dedicate a thought for Théodore who spent his last days helping me mentally to finish this study before leaving this world early.

\section{References}

Avraham, E 2000, 'Cities and their news media images', Cities, Vol. 17, No. 5. Elsevier Science Ltd, pp .363-370. PII: So264-2751(oo)ooo32-9, Great Britain.

Bassett, K 1993, 'Urban cultural strategies and urban cultural regeneration: a case study and critique', Environment and Planning A, Volume 25, pp. 1773-1788.

Beza, BB 2005, 'Volunteering in landscape architecture', Landscape Australia Vol. 105 (26(1)), Australian Institute of Landscape Architects (AILA). pp. 56-57.

Beza, BB 2010, 'The aesthetic value of a mountain landscape: A study of the Mt. Everest Trec', Landscape and Urban Planning Vol. 97. Elsevier Science Ltd. pp. 306317. doi: 10.1016/j.landurbplan.2010.07.003.

Castells, M 1977, The urban question; a marxist approach. Cambridge, MIT Press, Massachusetts.

Castells, M 1978, City, class, and power, Macmillan, London.

Castells, M 1996, The Rise of the Network Society, Blackwell, London, United Kindom.

Castoriadis, C 1987, The imaginary institution of society, Polity, Cambridge.

Cosgrove, D 1983, Social Formation and Symbolic Landscape, Croom Helm, London.

Cox, KR 1995, 'Globalisation, competition and the politics of local economic development', Urban Studies Vol. 32 (2), SAGE University of Glasgow. pp. 213-224.

Cheng, AS, Kruger, LE \& Daniels, SE 2003, "Place' as an integrating concept in natural resource politics: propositions for a social science research agenda', Society and Natural Resources Vol.16. Taylor and Francis Group. United States, Philadelphia. pp. 87- 104.

Czepczyński, M 2008, 'Cultural Landscapes of Post Socialist Cities: Representation of Powers and Needs. Hampshire/Burlington: Ashgate/ Book review by Ferenčohová S.', 2010, International Journal of Urban and Regional Research, Volume 34.2, June 2010, pp. 439-451, doi:10.1111/j.1468-2427.2010.00976.x.

Daniel, TC 2001, 'Whither scenic beauty? Visual landscape quality assessment in the $21^{\text {st }}$ century', Landscape and Urban Planning Vol. 54. Elsevier Science Ltd. pp. 267- 281.

Dimaggio, P 1982, 'Cultural entrepreneurship in nineteenth century Boston: the creation of an organizational base for high culture in America', Media, Culture and Society, Volume 4, pp. 33-50.

Duncan, J 1990, The City as Text: The Politics of Landscape Interpretation in the Kandyan Kingdom, Cambridge University Press, Cambridge.

Elizur, J 1994, 'Israel and the US: images of flawed paradise', Paper presented in the American- Israeli Relations and the 'New World Order' Conference, The Davis Institute of the Hebrew University of Jeresalem.

Erkip, F 1997, 'Social justice in the new era of city governance: the changing role of local governments in redistributive policies', Paper presented in AESOP XI, May 1997, Nijmegen, the Nederlands.

Erkip, F 2000, 'Global transformations versus local dynamics in Istanbul: Planning in a fragment metropolis', Cities, Vol. 17, No. 5. Elsevier Science Ltd. Great Britain. pp.371-377. PII: So264-2751(oo)ooo33-o.

Foucault, M 1993, 'Of other spaces: utopias and heterotopias', Architecture Culture 1943-1968: A Documentary Anthology, J. Ocman, Vintage, New York, pp. 420-426.

Gans, HJ 1979, Deciding What's News, Random House, New York, United States.

Gold, JR \& Ward, SV 1994, Place Promotion: The use of Publicity and Marketing to Sell Towns and Regions, John Wiley and Sons, Chichester.

Graber, DA 1989, 'Flashlight coverage: state news on national broadcasts', American Politics Quarterly, Vol. 17. SAGE Louisiana State University, Los Angeles, United States. pp. 277- 290.

Green, R 1999, 'Meaning and form in community perception of town character', Journal of Environmental Psychology Vol. 19. Academic Press Ltd. pp. 311-329. Article No. jevp.1999.0143.

Habe, R 1989, 'Public Design controls in American Communities', Town Planning Review Vol. 6o, Liverpool University Press. Great Britain. pp. 195-219.

Hadjimichalis, C \& Vaiou, D 1990, 'Flexible labour markets and regional development in northern Greece', International Journal of Urban and Regional Research, Volume 14.1, March 1990, pp. 1-24, doi:10.1111/j.14682427.1990.tboo818.x.

Hadjimichalis, C 2006, 'Non-Economic Factors in Economic Geography and in 'New Regionalism': A Sympathetic Critique', International Journal of Urban and Regional Research, Volume 30.3, September 2006, pp. 690-704, doi:10.1111/j.1468-2427.2006.00683.x.

Hadjimichalis, C \& Hudson, R 2006, 'Networks, Regional Development and Democratic Control', International Journal of Urban and Regional Research, Volume 30.4, December 2006, pp. 858-872, doi:10.1111/j.14682427.2006.00687.x.

Jackson, JB 1986, 'The vernacular landscape', Landscape Meanings and Values, EC Penning-Rowsell \& D Lowenthall, (eds), Allen \& Unwin, pp.65- 81, London, Great Britain.

Kaika, M 2010, 'Architecture and crisis: re-inventing the icon, re-imag(in)ing London and re-branding the City', Transactions of the Institute of British Geographers, pp. 453-474, doi: j.1475-5661.2010.00398.x.

Kaika, M 2011, 'Autistic Architecture: The fall of the icon and the rise of the serial object of architecture', Environment and Planning D: society and space, 29(6) $968-992$

Kant, I (JH Bernard, Trans.) 20oo, The Critique of Judgment, (Original Work Published 1790), Prometheus, Amherst.

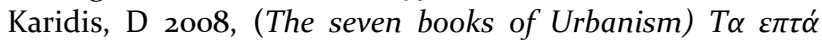

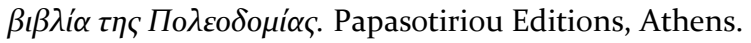

Kavoulakos, $\mathrm{K}$ 2006, Castoriadis on social imaginary and truth, Ariadne 12, pp. 201-213. 
Kulcsar, LJ \& Domokos, T 2005, 'The Post-Socialist Growth Machine : The Case of Hungary', International Journal of Urban and Regional Research, Volume 29.3, September 2005, pp. 550-563, doi:10.1111/j.1468-2427.2005.00605.x.

Mavromatidis, L 2010, '(Goutte d'Or: inside the obscure of the metropolis. Itineraries in a neighborhood in the North

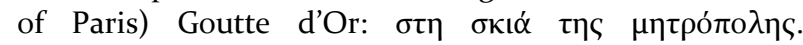

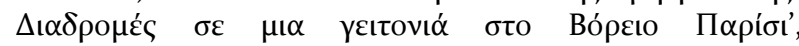
Geographies Vol. 16, Exantas, Athens, pp. 147-165. Mitchell, D 1996, The Lie of the Land: Migrant Workers and the California Landscape, University of Minnesota Press, Minneapolis.

Mitchell, D 200o, Cultural Geography: A Critical Introduction, Blackwell, Oxford.

Molotch, H 1976, 'The city as a growth machine: toward a political economy of place', American Journal of Sociology, Volume 82, pp. 309-332.

Molotch, H 1996, 'LA as product: how design works in a regional economy' in AJ Scott \& E Soja (eds.), The city: Los Angeles and urban theory at the end of the twentieth century, University of California Press, Berkeley and Los Angeles, pp. 225-275.

Ntaras, K 2001, 'Urban Cultural Identities and Globalization: A critical account', Culture $\mathcal{E}$ Communication (Kültür ve iletisim) Vol. 4 (1) Summer (Yaz), University of Ankara Turkey, p. 47-6o.

Prytherch, DL 2003, 'Urban planning and a Europe transformed: The landscape politics of scale in Valencia', Cities, Vol. 20, No. 6. Elsevier Science Ltd. Great Britain. pp.421-428. doi: 10.1016/j.cities.2003.08.0o8.

Porter, ME 1998, 'Clusters and the new economics of competiveness', Harvard Business Review December, pp. 77-90.

Putnam, R 1993, Making Democracy work, Princeton University Press, Princeton, NJ.

Ryan, C 1991, Prime Time Activism: Media Strategies for Gassroots Organizations, South End Press, Boston, United States.
Ryden, KC 1993, Mapping the Invisible Mind: Folklore, Writing and the Sense of Place, University of Iowa Press, Iowa City.

Sauer, C 1925, 'The morphology of landscape', University of California Publications in Geography Vol. 2. pp. 19-54.

Scott, JA 1997, 'The Cultural Economy of Cities', International Journal of Urban and Regional Research, Volume 21.2, June 1997, pp. 323-339, doi:10.1111/j.14682427.00075.

Sevenant, M \& Antrop, M 2007, 'Settlement models, land use and visibility in rural landscapes: two case studies in Greece', Landscape and Urban Planning Vol.8o. Elsevier Science Ltd. pp. 362- 374.

Southworth, M 1989, "Theory and practice of contemporary urban design', Town Planning Review Vol. 6o, Liverpool University Press. Great Britain. pp. 369- 402.

Strauss, AL 1961, Image of the American City, The Free Press, New York.

Tokatlí, N \& Boyací, Y 1999, 'The changing morphology of commercial activity in Istanbul', Cities, Vol. 16, No. 3. Elsevier Science Ltd. Great Britain. pp.181- 193. PII : So2642751(99)ooo15-3, doi:10.1016/So264-2751(99)ooo15-3.

Tuan, Y 1974, Topophilia: A Study of Environmental Perception, Attitudes and Values, Prentice - Hall, Englewood Cliffs.

Tuan, Y 1979, 'Though and landscape: the eye in the mind's eye' in: DW Meining (ed.), The Interpretation of Ordinary Landscapes: Geographical Essays. Oxford University Press, New York, pp. 89- 102.

Wynne, D(ed.) 1992, The culture industry, Avebury, Aldershot.

Žižek, S 1989, The sublime object of ideology, Verso, London. Žižek, S 1992, Enjoy your symptom! Jacques Lacan in Hollywood and out, Routledge, Chapman and Hall, New York and London.

Zukin, S 1991, Landscapes of power: from Detroit to Disney World, University of California Press, Berkeley and Los Angeles.

Zukin, S 1995, The cultures of cities, Blackwell, Oxford. 